$$
\text { DOE/ID/13283-TI-App.C-Pt. } 3
$$

\title{
The Aerocapacitor:
}

\section{An Electrochemical Double-Layer Energy-Storage Device}

\author{
S. T. Mayer ${ }^{*}$, R. W. Pekala, and J. L. Kaschmitter \\ Lawrence Livermore National Laboratory ${ }^{* *}$ \\ Livermore, Ca 94550
}

JES manuscript 92-05-054

Revised

\begin{abstract}
We have applied unique types of carbon foams developed at Lawrence Livermore National Laboratory (LLNL) to make an "aerocapacitor". The aerocapacitor is a high power-density, high energy-density, electrochemical double-layer capacitor which uses carbon aerogels as electrodes. These electrodes possess very high surface area per unit volume and are electrically continuous in both the carbon and electrolyte phase on a $10 \mathrm{~nm}$ scale. Aerogel surface areas range from 100 to $700 \mathrm{~m}^{2} / \mathrm{cc}$ (as measured by BET analysis), with bulk densities of 0.3 to $1.0 \mathrm{~g} / \mathrm{cc}$. This morphology permits stored energy to be released rapidly, resulting in high power densities $(7.5 \mathrm{~kW} / \mathrm{kg})$. Materials parameterization has been performed, and device capacitances of several tens of Farads per gram and per $\mathrm{cm}^{3}$ of aerogel have been achieved.

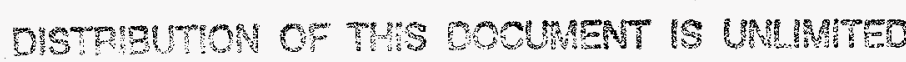

\section{INTRODUCTION}

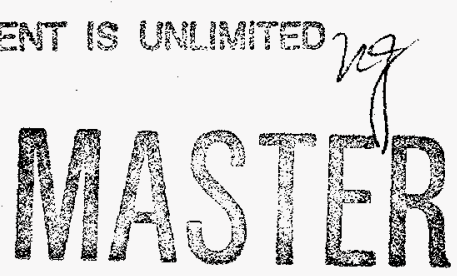

* Electrochemical Society Active Member.

** This work was performed under the auspices of the U.S. Department ef Energy by Lawrence Livermore National Laboratory under Contract Number W-7405-ENG-48.
\end{abstract}




\section{DISCLAMIER}

Portions of this document may be illegible in electronic image products. Images are produced from the best available original document. 
The storage of electrical energy based on the separation of charged species in an electrolytic double layer is inherently simpler and more reversible than in secondary batteries. Indeed, in most cases the cycle life of electrochemical double-layer capacitors (EDLCs) is limited by the device packaging and not by degradation of the device components. Though all electrode/electrolyte interfaces exhibit double-layer capacitance, only devices which do not exhibit faradaic reactions over the potential range of operation (i.e. are ideally polarizable) are considered EDLCs. Recently, the transition between "supercapacitors" and batteries has been discussed (1), with some researchers ascribing attributes of both batteries and capacitors to certain devices that are said to exhibit "pseudocapacitance" (2) (i.e. 2-dimensional reversible faradaic surface reactions). This paper analyzes the characteristic double-layer capacitance of the aerocapacitor.

The capacitance of the $\mathrm{Hg} /$ electrolyte interface is the most thoroughly studied, providing much of our understanding of the structure of the electric double layer. From these studies, typical capacitance values of 10 to $20 \mu \mathrm{F} / \mathrm{cm}^{2}$ are obtained for single electrodes in concentrated aqueous electrolytes. Since the energy of a capacitor is given by $E=1 / 2 \mathrm{CV}^{2}$, where $\mathrm{C}$ is the device capacitance and $\mathrm{V}$ is the applied voltage, an aqueous device operating at 1.2 volts provides a maximum energy of $3.6 \mu \mathrm{J} / \mathrm{cm}^{2}$. Because capacitance is proportional to surface area, only electrochemically inen materials of the highest specific surface area can be utilized in making a viable rechargeable EDLC energy storage device. The use of EDLCs has been largely limited to applications where very high cycle life is required and very low energy density is permissible (e.g. memory retention in integrated circuits (ICs) or clocks). Cycle lives of well over 100,000 have been demonstrated in EDLC devices (3). Unlike conventional batteries, where electrode 
polarization can greatly diminish power, EDLCs can deliver very high specific power.a Research on improving the energy and power densities of EDLCs has been driven by both military and commercial load leveling applications. Next generation EDLCs promise to deliver longer life and higher energy and power densities than achieved previously.

Recently several capacitors using high surface area electrodes (composed of activated carbon composites or $\mathrm{RuO}_{2}$ based composites) have been introduced. Activated carbon and activated carbon fiber cloths (ACFCs) can be produced inexpensively with up to $2000 \mathrm{~m}^{2} / \mathrm{g}$ of surface area (as measured by gas absorption). This value would correspond to a single electrode capacitance of $400 \mathrm{~F} / \mathrm{g}(72 \mathrm{~J} / \mathrm{g}$ carbon in a $1.2 \mathrm{~V}$ device) if all of the surface area were electrochemically accessible. However, typical activated carbon capacitances are around $40 \mathrm{~F} / \mathrm{g}$ carbon, or about $1 / 10$ th of this value (4). It is well known that activated carbons contain a significant fraction of micropores $(<\mathrm{nm})(5)$. We believe that the above differences are associated with the inability of the solution to wet the micropores and/or the inability of a double layer to be form in a region where the pore dimensions are on the same size scale as that of the double layer. Therefore, quantitative measurement of surface area by standard gas-absorption techniques (e.g. BET analysis) can not be used to estimate double-layer capacitance unless the pore size distribution is also known.

Although devices using pariculate carbons have high energy-density, in most cases the internal resistances are also high due to the interparicle contact resistance. To minimize these problems, several different techniques for fabricating high-surface-area carbon electrodes with improved interparicle contact have been developed. These involve

a A distinction must be made between what Conway refers to as 2-D faradaic "pseudocapacitance" and EDLCs. In the former case, the process still suffers from 2-D polarization effects while the latter does not. Both types of systems have high power densities. 
compression spiral winding, binding the active materials with teflon ${ }^{\circledR}$, pyrolyzing carbon powder/phenol-formaldehyde mixtures (7), or loading the carbon-electrode matrix with metal (8).

The use of organic electrolytes in capacitors has also been of interest due to their higher operating voltage $(6,7)$. In addition to offering much higher energy densities, one pair of electrodes can supply sufficient voltage to support memory retention. A disadvantage of organic electrolytes is that they typically have lower power densities (due to higher resistivity) than aqueous systems. Unlike lithium rechargeable batteries, where the choice of electrolyte is limited by the often competing effects of the electrode passivation and electrolyte conductivity, the use of organic electrolytes in the EDLC is potentially less restrictive.

LLNL has developed a unique family of open-cell carbon aerogel foams. The porosity and surface area of these materials can be controlled over a broad range, while the pore size and particle size can be tailored at the nanometer scale (9). Because of their unique nanostructure, carbon aerogels were expected to be excellent EDLC electrodes. We have performed a comprehensive study of this material, demonstrating its potential for high power and energy density.

\section{EXPERIMENTAL}

The preparation of organic aerogels and their carbonized derivatives has been described previously $(10,11)$. Briefly, resorcinol and formaldehyde (1:2 molar ratio) were dissolved in an appropriate amount of deionized/distilled water, and sodium carbonate was added as a base catalyst. The resorcinol-formaldehyde (RF) solution was poured into glass vials which were then sealed and cured at elevated temperature. For solutions containing $>10 \%$ reactants, the cure cycle included 1 day at room temperature followed by 1 day at 
$50^{\circ} \mathrm{C}$ and 3 days at 85 to $90^{\circ} \mathrm{C}$. [Resorcinol]/[Catalyst] (R/C) ratios of 50 to 300 were used to form transparent gels, while opaque gels were formed at $R / C$ values of $>400$.

The "aquagels" were placed in an agitated acetone bath and washed for several days to ensure complete replacement of the water which originally occupied the pores of the RF gel. The acetone-filled gels were then placed in a jacketed pressure vessel that was subsequently filled with liquid carbon dioxide. The RF gels were exchanged with fresh $\mathrm{CO}_{2}$ until the acetone was completely flushed from the system. The pressure vessel was taken above the critical point of carbon dioxide $\left(\mathrm{T}_{\mathrm{C}}=31^{\circ} \mathrm{C} ; \mathrm{P}_{\mathrm{C}}=7.4 \mathrm{MP}_{\mathrm{a}}\right)$ and held at $\sim 45^{\circ} \mathrm{C}$ and $\sim 11 \mathrm{MP}_{\mathrm{a}}$ for a minimum of 4 hours. While maintaining the temperature, the pressure was slowly bled from the vessel overnight. At atmospheric pressure the dark red RF aerogels were removed from the vessel and then pyrolyzed at $1050^{\circ} \mathrm{C}$ in an inert atmosphere to form a vitreous carbon aerogels.

The resultant carbon aerogels were cylindrical in shape, with diameters ranging from 1 to $1.75 \mathrm{~cm}$ and bulk densities of 0.3 to $1.0 \mathrm{~g} / \mathrm{cc}$. The final density of the carbon aerogels is dependent on both the starting reactant concentration (R) and the $R / C$ ratio. Prior to cutting, the carbon aerogel cylinders were immersed in deionized water, and the pressure was cycled from $100 \mathrm{~Pa}$ to $200 \mathrm{kPa}$ for 1 day. Though the carbon aerogels very rapidly wet with electrolyte when immersed, this vacuum/pressurization procedure was performed to ensure complete filling of the smallest pores within the aerogel.

Wet carbon aerogel cylinders were placed in a holding jig and cut into $1.25 \mathrm{~mm}(50$ mil) thick "wafers" using a diamond blade dicing saw. The applied cutting weight was varied depending upon the aerogel density. The aerogel wafers were then immersed in an aqueous $4 \mathrm{M} \mathrm{KOH}$ solution for at least 1 day, thereby allowing the $\mathrm{KOH}$ to diffuse into the pores. The volume of electrolyte was much greater than the volume of deionized water in 
the pores of the aerogel, thus the concentration of the electrolyte was not significantly diluted by this procedure. In general, oxygen was not removed from the solution. No significant differences were observed between identical samples that were left immersed in the electrolyte for longer times or in deoxygenated solutions.

Two aerogel wafers of identical composition, diameter, and thickness were pressed together with two non porous carbon rods inside a teflon cylinder, as shown in Figure 1. The two aerogel wafers were separated by an electrolyte wetted microporous glass separator. Exmet ${ }^{\circledR}$ nickel mesh was placed on each end of the carbon rods to provide a low resistance contact. Two polybutadiene o-rings were sleeved around the carbon rods and with the contact are pressed by a vise against the cylinder to form a seal.

The measurement of the capacitance was performed by integrating the current over time, following a step change in potential. Each capacitor was placed in series with a $1 \Omega$ resistor. The voltage across the resistor was sampled once each second by a computer, and the corresponding current was calculated using Ohm's law. Both the current and charge were recorded. Up to 8 cells were simultaneously charged and discharged between 0.0 and $1.0 \mathrm{~V}$ for 1000 second periods each for several days.

In order to measure accurately the internal resistance of the cells, they were tested without the large external load. Potentiostatic current transients were collected on a computer controlled EG\&G PAR 273 potentiostat, allowing the measurement of transients at nearly short-circuit conditions. When the total load (including all internal and enternal resistances from the cell) connected to the potentiostat is small, the initial current following a potential step can be very large. Because the maximum current of the potentiostat is $1 \mathrm{~A}$, we typically charged and discharged the cells with small potential differences (less than 150 
$\mathrm{mV}$ ). Data was recorded at $25 \mathrm{~ms}$ intervals (see the section entitled "Discharge Behavior" below).

\section{RESULTS}

Carbon Aerogel Structure- Several macroscopic and microscopic material properties of the carbon aerogels have been shown to depend on two parameters: the initial reactant concentration $(\mathrm{R})$ and the [Resorcinol]/[Catalyst] ratio $(\mathrm{R} / \mathrm{C})$. Most notable of these are the compressive modulus thermal conductivity, electrical conductivity, surface area, and density $(9,10,12-14)$.

The effects of the above parameters on the bulk density of carbon aerogels are shown in Figure 2. As expected, the aerogel density increases with the starting reactant concentration ( $R$ ). An inverse relationship with the R/C ratio is observed; however, the density does not decrease significantly for $\mathrm{R} / \mathrm{C}$ values greater than 300 . In fabricating a useful EDLC, a high-density carbon aerogel is needed so that reasonable capacitance density $\left(\mathrm{F} / \mathrm{cm}^{3}\right)$ and specific capacitance ( $\mathrm{F} / \mathrm{g}$ carbon +electrolyte) are obtained.

The specific surface area of carbon aerogels ( 500 to $850 \mathrm{~m}^{2} / \mathrm{gm}$ ) shows an inverse dependence upon the $\mathrm{R} / \mathrm{C}$ ratio and reflects differences in the size of the interconnected particles (14). Furthermore, the specific surface area can be controlled over a narrow range independent of the aerogel density. Figure 3 shows transmission electron micrographs of carbon aerogels synthesized at $\mathrm{R} / \mathrm{C}=50$ and $\mathrm{R} / \mathrm{C}=300$. Particle diameters of $\sim 9 \mathrm{~nm}$ and $\sim 15$ nm are observed, respectively.

Two pore-size regimes can be differentiated in carbon aerogels (9): (a) mesopores ( 2 to $50 \mathrm{~nm}$ ) that span the distance between the interconnected particle chains and (b) micropores $(<2 \mathrm{~nm})$ that primarily reside within the individual particles. As expected, the 
mesopore size decreases with increasing aerogel density as a result of increased particle packing. For carbon aerogels synthesized at $\mathrm{R} / \mathrm{C}=200$, the average mesopore size (diameter) displays a power-law dependence on density such that:

$$
\mathbf{d}=3.86 \pm 0.40 \rho^{-1.05 \pm 0.05}
$$

where $\mathrm{d}$ is the diameter in $\mathrm{nm}$ and $\rho$ is the bulk density in $\mathrm{g} / \mathrm{cc}$. Gas-adsorption analysis shows that the individual particles are microporous, having a narrow distribution centered at around $0.6 \mathrm{~nm}$. It is doubtful that this microporosity contributes to electrochemical double-layer formation since electrolyte penetration and/or double-layer polarization are questionable on this scale. We believe that the double layer is primarily formed at the surface of the individual particles in the mesopore region.

Capacitance Measurements- Figure 4 gives the charge and discharge capacitance of a two-electrode device (constructed as shown in Figure 1), as a function of cycle number. All of the aerogel samples studied exhibited similar behavior. Initially the ratio of the charge to discharge capacitance is large (about 1.27), but after several cycles this ratio approaches one. This result implies that a diminishing, irreversible faradaic reaction(s) is occurring during the first few charging cycles. A cumulative toul amount of 27 coulombs of charge or $72 \%$ of the reversible charge capacitance is irreversibly consumed by these reactions and is possibly associated with the oxidation/reduction of loosely bound surface groups on the carbon aerogel electrode. Several authors have discussed the possible "pseudocapacitive" behavior of quinone to hydroquinone conversions of attached surface groups on carbon materials (15-18). Generally, it is believed that such groups are active 
only after holding the potential at a large value $(>1.75 \mathrm{~V})$ for several minutes. The fact that these cells were cycled at lower voltages (i.e. without surface-preparation procedures) and that they showed rapid current-transient responses (see below) supports our belief that the capacitance of the carbon aerogels did not involve any "pseudocapacitive" effects.

Detailed analysis of the data reveals that the capacitance of the cells typically decreased at a rate of about $2.5 \% /$ day. This slow decrease in capacitance was due to electrolyte evaporation through the o-ring seal. This was demonstrated by disassembling the cell and adding electrolyte, thereby restoring the cell to its original capacitance. Cells with replenished electrolyte did not exhibit the initial charge to discharge capacitance differences seen in newly constructed cells, revealing that the carbon electrode, and not the electrolyte, appears to be the source of the faradaic irreversibility.

The specific capacitance (F/g carbon) of several different carbon aerogels versus their dry bulk density is shown in Figure 5.b For a fixed R/C ratio, the specific capacitance decreases with increasing density. Aerogels formulated with the same R/C ratio will contain interconnected particles of approximately the same size, but the number of particles per unit volume will increase in proportion to the aerogel density. The resulting increased interparticle contact improves mechanical properties and provides higher electrical conductivities; however, the accessible surface area per particle and per gram of carbon decreases. We attribute the decrease in specific capacitance with respect to density as due to a decrease in the individual particle surface area resulting from interparticle contact. Figure 6 shows the capacitance density $\left(\mathrm{F} / \mathrm{cm}^{3}\right)$ as a function of aerogel density for several

b All of the data presented here are for the capacitance of a two electrode device as shown in Figure 1, and not that of an half cell or individual electrode. This is important to note because with two-electrode capacitors in series, the 1) capacitances of the two individual electrodes add as the reciprocal of their sum, and 2) twice the mass (or volume) of electrode is required. Most data reponed in the literature is for a single electrode, and is therefore typically four times as great as the values shown here. 
$\mathrm{R} / \mathrm{C}$ formulations. There is an approximately linear increase in capacitance density with aerogel density (slope $31 \mathrm{~F} / \mathrm{g}$ ) in the range of 0 to $0.50 \mathrm{~g} / \mathrm{cc}$. However, the capacitance of the highest density samples (which are all of an R/C 50 formulation) is nearly constant (in the range from $0.5 \mathrm{~g} / \mathrm{cc}$ to $1.008 \mathrm{~g} / \mathrm{cc}$ ) with a maximum value of $26.4 \mathrm{~F} / \mathrm{cm}^{3}$. For these densities and formulations, the effect of the decreasing individual particle capacitance, due to the decreasing effective particle surface area associated with increasing interparticle contact, appears to balance the effect of increasing the bulk density.

The specific capacitance of the aerogels, per weight of carbon plus $4 \mathrm{M} \mathrm{KOH}$ electrolyte, is of interest because it more accurately conveys data needed to determine device specific energy. This information is shown in Figure 7. Like the capacitance density, the specific capacitance increases with density up to about $0.5 \mathrm{~g} / \mathrm{cc}$, above which the capacitance remains nearly constant with a maximum value of $19.2 \mathrm{~F} / \mathrm{g}$ carbontelectrolyte. Assuming a 1.2 volt charge, this capacitance corresponds to an energy density of $13.8 \mathrm{~J} / \mathrm{g}$ of carbon plus electrolyte $(3.85 \mathrm{~W} \cdot \mathrm{hr} / \mathrm{kg}$ carbon+electrolyte). More recent material developments and incorporation of different electrolytes have yielded performance improvements that exceed the requirement of the U.S. Department of Energy DLC's in electric vehicles $(5 \mathrm{~W} \cdot \mathrm{hr} / \mathrm{kg})$, and will be reported at a later date.

The specific capacities ( $\mathrm{F} / \mathrm{g}$ carbon) of several samples of the same reactant concentration $(\mathrm{R}=30 \%)$ are shown in Figure 8. Varying the $\mathrm{R} / \mathrm{C}$ ratio from $\mathrm{R} / \mathrm{C} 50$ (particle size $\sim 9 \mathrm{~nm}, 0.8 \mathrm{~g} / \mathrm{cm}^{3}$ ) to R/C 900 (particle size $\sim 65 \mathrm{~nm}, 0.3 \mathrm{~g} / \mathrm{cm}^{3}$ ) has litule effect on the specific capacitance. Though at first one might expect samples with low R/C ratios to exhibit higher specific capacitances than high $\mathrm{R} / \mathrm{C}$ samples (because of the corresponding smaller particle size), the particles tend to be more clumped and compacted together at the higher densities. This again demonstrates the competing effects of particle size and bulk density on the specific capacities of the aerocapacitor. 
Discharge Behavior- The current-transient response of a simple capacitor (i.e. without distributed capacitance) to a step change in potential is given by: $c$

$$
i=\frac{\Delta V}{R} \exp \left(\frac{-t}{R C}\right)
$$

where $i$ is the total current, $R$ is the total system resistance (internal and external, ohms), $\Delta \mathrm{V}$ is the magnitude of the potential step (volts), $\mathrm{C}$ is the capacitance of the electrodes (Farads), and $t$ is the time (seconds). The total resistance of the system can be determined from the maximum current, which occurs immediately after the potential step $(t=0)$. The ratio of the integrated current over the voltage gives the capacitance.

The capacitance of the aerogel electrode is complicated by the distributed nature of the porous surface. Posey and Morozumi (19) presented the theoretical response of a porous EDLC to galvanostatic and potentiostatic charging. They derived their result by applying the definition of capacitance to a differential pore element, using Ohm's law to relate the potential to the current flux within the one dimensional pore, and by applying the appropriate boundary conditions for the case of interest. Tiedemann and Newman (20) recast Posey and Morozumi's result in a form which easily allows the inclusion of separator, lead, and matrix resistance effects. Their result can be expressed as (20)

c Equations in this section are strictly true only for systems in which the capacitance is independent of voltage (i.e. the differential capacitance is constant). 


$$
\begin{gathered}
I=\sum_{n=1}^{\infty} \frac{\exp \left(-T X_{n}^{2}\right)}{1+\lambda+\lambda^{2} X_{n}^{2}} \\
I=\frac{i L}{\Delta V K} \quad T=\frac{t K}{C L^{2}} \quad \lambda=\frac{R K}{I}
\end{gathered}
$$

where $\mathrm{i}$ is the current density $\left(\mathrm{A} / \mathrm{cm}^{2}\right), \mathrm{L}$ is the electrode thickness $(\mathrm{cm}), \Delta \mathrm{V}$ is the step change in voltage (volts), $\mathrm{K}$ is the effective electrolyte conductivity, $\mathrm{t}$ is the time, $\mathrm{C}$ is the capacitance density of the half electrode $\left(F / \mathrm{cm}^{3}\right), X_{n}$ is the positive roots of the equation $\cot \left(X_{n}\right)-\lambda X_{n}=0$, and $R$ is a system resistance defined by

$$
R=\frac{L_{s}}{K_{s}}+\frac{I_{s}}{\sigma+\kappa}+R_{L}
$$

with $\mathrm{L}_{S}$ being the separator length $(\mathrm{cm}), \mathrm{K}_{\mathrm{S}}$ the effective conductivity of the electrolyte in the separator, $\sigma$ the porous matrix conductivity, and $\mathrm{R}_{\mathrm{L}}$ an external resistance. Equation 3 is dimensionless and emphasizes the relative importance of the dimensionless groups of which it is composed. The dimensionless current, I, might be considered as being composed of an infinite series of elements which discharge at varying rates (i.e. have different $\mathrm{RC}$ time constants) with respect to dimensionless time, $\mathrm{T}$. The parameter $\lambda$ is a 
dimensionless resistance containing information about the relative importance of the porous electrode's electrolyte resistance relative to the resistance outside the pore. It acts as a weighting function for the various elements.

Because the conductivity of the aerogel matrix (as determined by 4 point-probe measurement) (21) is from 10 to 80 times that of the bulk electrolyte ( 5 to $40 \Omega^{-1} \mathrm{~cm}^{-1}$ ), the middle term of equation 4 is small ( 3 to $23 \mathrm{~m} \Omega \mathrm{cm}^{2}, 1.25 \mathrm{~mm}$ thick electrode). This is in sharp contrast with materials composed of compressed powders, where the matrix resistance term can be comparable to, or greater than, that of the electrolyte (22). An equivalent circuit of the porous electrode is shown in Figure 9, where, at the limit, each capacitor element becomes increasingly small, while the number of elements increases. Nevertheless, Tiedemann and Newman (20) note that the total resistance of the system is invariant with regard to the nature of the capacitance distribution, and can be determined by the relation:

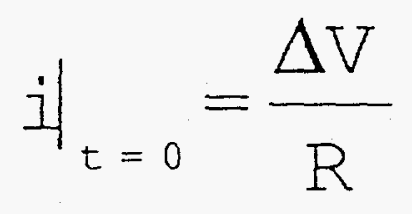

This can be shown by taking the limit of 2 or 3 as $t$ goes to zero. In this manner, we were able to distinguish between the resistance of the components (separator, lead resistance, contact resistance, etc.) from that of the electrolyte in the carbon aerogel.

The observed current discharge of a $0.60 \mathrm{~g} / \mathrm{cc}$ sample $(\mathrm{R} / \mathrm{C}=200)$ from 0.1 to $0.0 \mathrm{~V}$ is shown in Figure 10, along with two best-fit modeled discharges (PE=porous electrode model, equation 3 , and $\mathrm{RC}=$ simple resistive model, equation 2 ). The $\mathrm{RC}$ model does not include the distributed nature of the capacitance and therefore does not accurately represent 
the discharge behavior. The PE model fits the observed curve better. However, significant disparities between the two curves are observed immediately following the potential step $(<400 \mathrm{~ms})$. Table 1 lists the experimental and modeled physical parameters (from equation 3). The experimental value of $R$ is determined from equation 5 , and $K / L$ is estimated from the equation presented by De La Rue and Tobias for effective conductivities of particle dispersions $(20,23,24)$. While the results show good agreement between the observed and modeled capacitance, agreement between the resistance external to the pore $(R)$ and internal conductivity (K/L) are not as good. This may indicate that some as yet undetermined mechanism aids the discharge at early times (e.g. double-layer ion-ion repulsion at opposing sides of a pore).

Table 1

\begin{tabular}{|l|l|l|l|}
\hline Parameter & Experimental & PE Model & RC Model \\
\hline Capacitance $\left(\mathrm{F} / \mathrm{cm}^{3}\right)$ & 24.1 & & \\
\hline Resistance $\left(\Omega \mathrm{cm}^{2}\right)$ & 0.302 & 23.3 & 24.4 \\
\hline & & & 0.497 \\
\hline $\operatorname{KL}\left(\Omega^{-1} \mathrm{~cm}^{-2}\right)$ & 1.81 & & \\
\hline
\end{tabular}

The resistance of the leads and contact $(85 \mathrm{~m} \Omega)$ was determined by assembling the cell without the separator and electrolyte. The potentiostat lead resistance is approximately $40 \mathrm{~m} \Omega$, and the resistance through the Exmet current collector, carbon rods, and interfacial contacts to the aerogels was an additional $45 \mathrm{~m} \Omega$. This resistance was distributed over 2.2 $\mathrm{cm}^{2}$ of aerogel surface, resulting in an external lead resistance of $187 \mathrm{~m} \Omega \mathrm{cm}^{2}$ (1ast term, equation 4). After calculating an electrode resistance of $5 \mathrm{~m} \Omega \mathrm{cm}^{2}$ (middle term in equation 
4), we estimate that the $0.38 \mathrm{~mm}$-thick porous-glass separator (thickness prior to compression) added an additional $110 \mathrm{~m} \Omega \mathrm{cm}^{2}$.

From these results, the instantaneous peak power density of an aerogel device can be estimated. If we assume that the peak current density increases linearly with voltage (see equation 2 or 3), and using a reasonable maximum voltage per bipole of $1.2 \mathrm{~V}$ (limited by the decomposition of water), then the maximum short circuit current is $1.2 \mathrm{~V} /$ $\left(0.302 \Omega \mathrm{cm}^{2}\right)=4.0 \mathrm{~A} / \mathrm{cm}^{2}$ if all sources of resistance in our test are included. The maximum power is obtained by

$$
P_{\max }=\left[\frac{1^{2} R}{4}\right]=\left[\frac{1^{2}}{4 R}\right]
$$

with $\mathrm{i}$ being determined experimentally and/or $\mathrm{R}$ being determined using equation 5 . Using equation 6 results in a maximum power of $1.2 \mathrm{~W} / \mathrm{cm}^{2}$. The mass $/ \mathrm{cm}^{2}$ of the two $1.27 \mathrm{~mm}$ thick electrodes was $0.154 \mathrm{~g}$, so this corresponds to a maximum power density of 7.7 $\mathrm{kW} / \mathrm{kg}$ carbon. It should be noted that the above results are sensitive to a number of factors, many of which could be varied to decrease the internal resistance and increase power density (e.g. decrease separator thickness, lead resistance, electrode thickness, different pyrolysis temperatures, etc.). By using thinner films of aerogel material and separators, the power densities may be increased substantially. 


\section{CONCLUSIONS}

We have shown that, because of their unique nanostructure, carbon aerogels exhibit large (specific) capacities and capacitance densities (several tens of farads per gram and $\mathrm{cm}^{3}$ ). This stored energy can be released rapidly and efficiently because of the contiguous structure of the carbon electrode. The capacitance density increases with aerogel density up to a point where interparticle contact decreases usable surface area. This effect occurs at aerogel densities above $\sim 0.5 \mathrm{~g} / \mathrm{cc}$. Samples synthesized at $\mathrm{R} / \mathrm{C}=50$ have the smallest particle size $(\sim 9 \mathrm{~nm})$ and appear to provide the best capacitance.

We have modeled the behavior of the aerocapacitor using both a simple RC discharge model and a more complex, distributed porous electrode model. The aerocapacitor best fits the porous electrode model. The results agree with other electrical resistance measurements and indicate that, because of the excellent continuity inherent in the aerogel matrix, interparticle contact resistance is low.

The aerocapacitor has the potential to provide substantial new capabilities as a lowcost, high-power and high energy-density capacitor.

\section{ACKNOWLEDGMENTS}

We thank Nick Colella of LLNL for his many valuable technical and programmatic contributions. Fung Ming Kong and Cynthia Awiso provided valuable suppon on the synthesis and processing of carbon aerogels samples. This work was supported by SDIO/TN, and Lawrence Livermore National Laboratory under Contract Number W-7405ENG-48 to the U.S. Departement of Energy'. 


\section{REFERENCES}

1 B. E. Conway, This Journal, 123, 1539 (1991)

2 B.E. Conway, Prog. Surf. Sci., 16, 1 (1984).

3 A. F. Burke, "Ultracapacitors for Electric Vehicle Applications", in $1^{\text {st International }}$ Seminar on Double Layer Capacitors and Similar Energy Storage Devices, December 9-11, 1991, Deerfield Beach, Florida. S.P. Wolsky and N. Marincic, organizers. Florida Educational Seminars, Boca Raton, Fl.

4 I. Tarahashi, A. Yoshida, and A. Nishino, Bull. Chem. Soc. Jpn. 63, 3611 (1990).

5 I. Tamahashi, A. Yoshida, and A. Nishino, This Journal, 137, 3052 (1990).

6 Morimoto, T., K. Hiratsuka, Y. Sanada, H. Aruga, U.S. Pat. \#4,725,927, Feb. 16, 1988.

7 Tabuchi, Junji, Takashi Saito, and Keitaro Katsu, "Activated Carbon/Carbon Composite

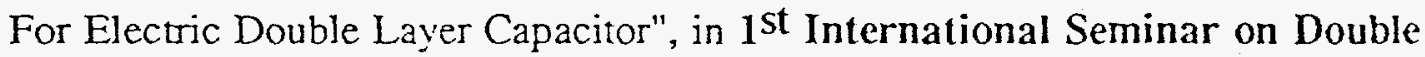
Layer Capacitors and Similar Energy Storage Devices, December 9-11, 1991, Deerfield Beach, Florida. S. P. Wolsky and N. Marincic, organizers. Florida Educational Seminars, Boca Raton, Fl.

8 D. A. Kohler, J. Zabasajja, F. Rose, and J.J. Tatarchuk, This Journal, 137, 1750 (1990). 
9 R. W. Pekala and C. T. Alviso, "Carbon Aerogels and Xerogels," in Novel Forms of Carbon, D. Cox, J. Pouch, and C. L. Renschler, eds., Mat. Res. Soc. Symp. Proc. (1992), in press.

10 R. W. Pekala and F.M. Kong, Polymer Prpts, 30 (1), 221, (1989).

11 R. W. Pekala, J. Mat. Sci., 24, 3221 (1989).

12 R. W Pekala., L.W. Hrubesh, T. M. Tillotson, C. T. Alviso, J.F. Poco, and J. D. LeMay, Mat. Res. Soc. Symp. Proc., 207, 1991.

13 R. W. Pekala, C. T. Alviso and J. D. LeMay, J. Non-Crystal. Solids, 125, 67 (1990).

14 R. W. Pekala, C. T. Alviso, and J. D. Lemay, "Organic Aerogels: A New Type of Ultrastructured Polymer," in Chemical Processing of Advanced Materials, L.L. Hench and J. K. West, eds., John Wiley and Sons, New York, 1992, pp. 671683.

15 T. Nagaoka and T. Yoshino, Anal. Chem. 58, 1037 (1986).

16 Royce Engstrom, Anal. Chem., 54, 2310 (1982).

17 Vesna Markovic, Nikola Vukelic and Dragan Markovic, Fuel, 68, 1039 (1989).

18 Jarzy Zak and Theodore Kuwana, Am. Chem. Soc., 104, 5514 (1982).

19 F. A. Posey and T. Morozumi, This Journal, 113, 176 (1966).

$20 \mathrm{~W}$. Tiedemann and J. Newman, This Journal, 122, 70 (1975).

21 X. Lu, O. Nilsson, J. Fricke, and R. W. Pekala, J. Appl. Phys., Submitted. 
22 B. Reichman and E. Mrotek, "Electrical Characteristics of Double Layer Capacitors Using Different Carbon Layer Designs", in $\mathbf{1}^{\text {st }}$ International Seminar on Double Layer Capacitors and Similar Energy Storage Devices, December 9-11, 1991, Deerfield Beach, Florida. S. P. Wolsky and N. Marincic, organizers. Florida Educational Seminars, Boca Raton, Fl.

23 R. E. De La Rue and C. W. Tobias, This Journal, 106, 827 (1959).

23 R. E. Meredith and C. W. Tobias, "Conduction in Heterogeneous Systems", in Advances in Electrochemistry and Electrochemical Engineering, P. Delahay and C.

Tobias, ed., Vol. 2, pg 15-48. 1962.

\section{DISCLAIMER}

This report was prepared as an account of work sponsored by an agency of the United States Government. Neither the United States Government nor any agency thereof, nor any of their empleyees, makes any warranty, express or implied, or assumes any legal liability or responsibility for the accuracy, completeness, or usefulness of any information, apparatus, product, or process disclosed, or represents that its use would not infringe privately owned rights. Reference herein to any specific commercial product, process, or service by trade name, trademark, manufacturer, or otherwise does not necessarily constitute or imply its endorsement, recommendation, or favoring by the United States Government or any agency thereof. The views and opinions of authors expressed herein do not necessarily state or reflect those of the United States Government or any agency thereof. 


\section{FIGURE CAPTIONS}

Figure 1) Schematic of experimental apparatus for testing Aerogel carbon capacitance. Note that the measured values reported in this paper correspond to that of a device and not of a single electrode.

Figure 2) The density of Aerogel carbon versus the ratio of resorcinol and formaldehyde (1:2 molar ratio) to catalyst (R/C).

Figure 3) Transmission Electron Micrograph (TEM) of carbon Aerogels prepared at different resorcinol and formaldehyde (1:2 molar ratio) to catalyst ratios (R/C).

Figure 4) Change in charge and discharge capacitance of the Figure 1 test device with cycling. Reactant concentration $30 \%$ by weight (1:2 molar ratio of resorcinol and formaldehyde). Ratio of resorcinol and formaldehyde to catalyst (R/C) $=400$.

Figure 5) Specific capacitance (based on weight of dry arbon) of the Figure 1 test device for various Aerogel carbon formulations.

Figure 6) Capacitance density of the Figure 1 test device for various Aerogel carbon formulations.

Figure 7) Specific capacitance (based on weight of carbon plus electrolyte) of the Figure 1 test device for various Acrogel carbon formulations.

Figure 8) Capacitance of the Figure 1 test device for various R/C ratio Aerogel carbon fomulations with a fixed concentration of reactants (i.e. $30 \%$ ).

Figure 9) Aerocapacitor equivalent circuit diagram. 
Figure 10) Observed discharge performance vs. different models for Figure 1 test device. 


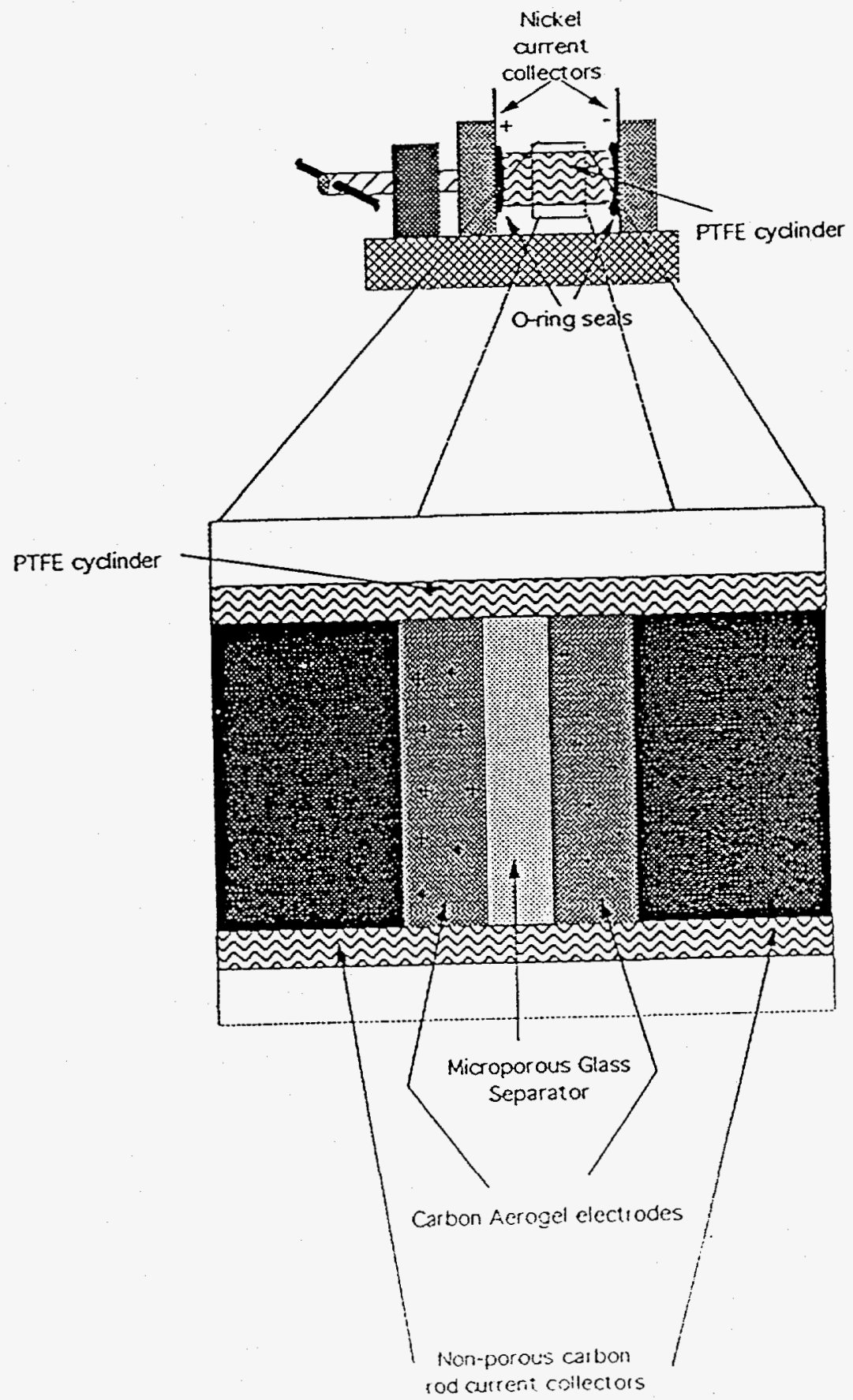

Figure 1 


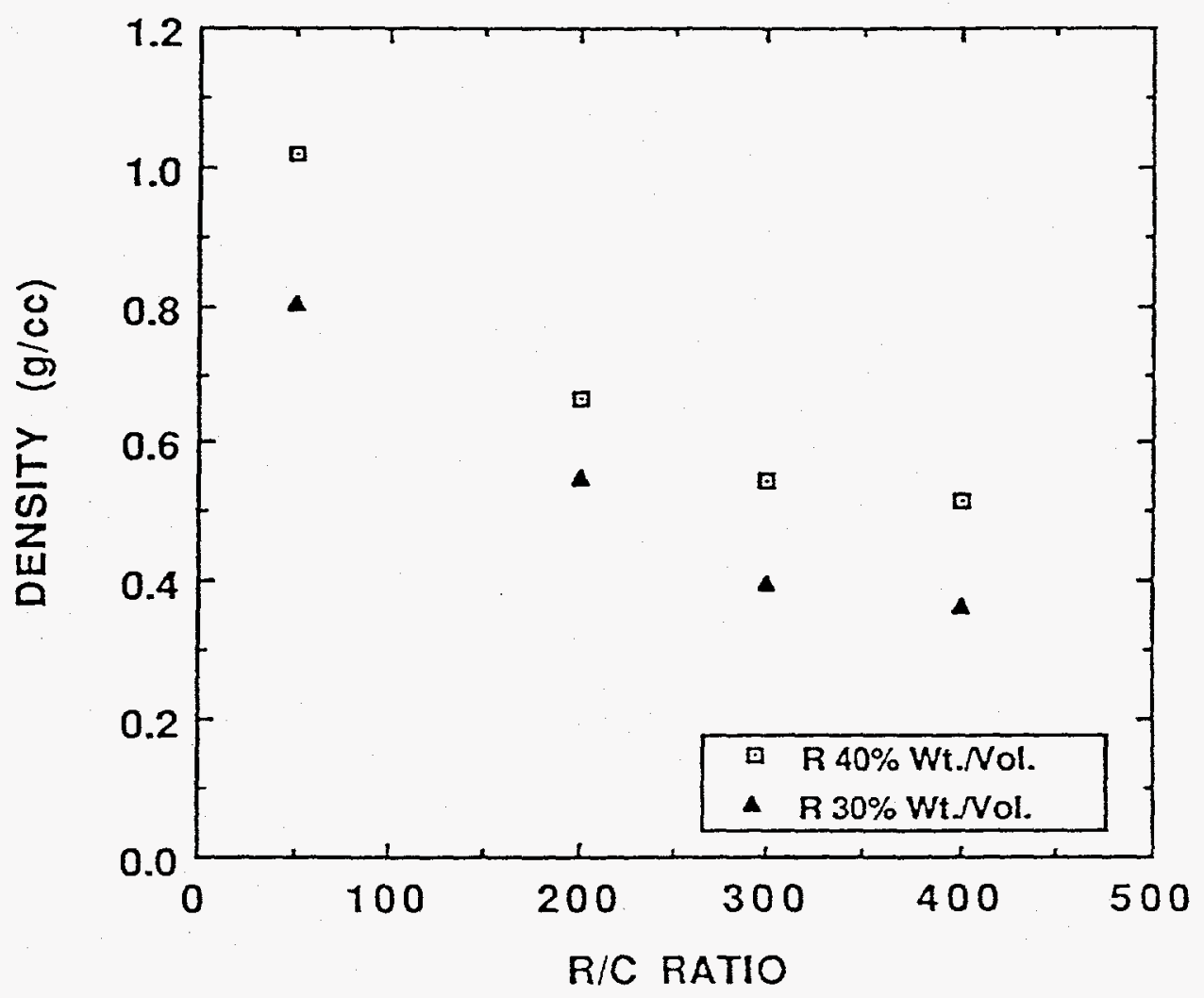

Figure 2 


$$
\mathrm{R} / \mathrm{C}=50
$$

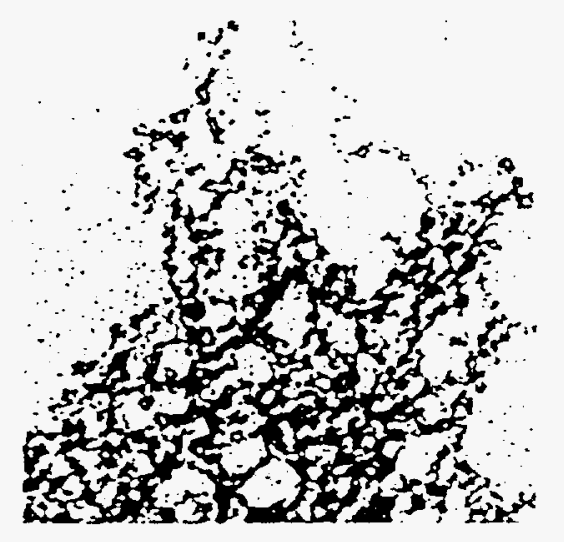

$$
R / C=300
$$

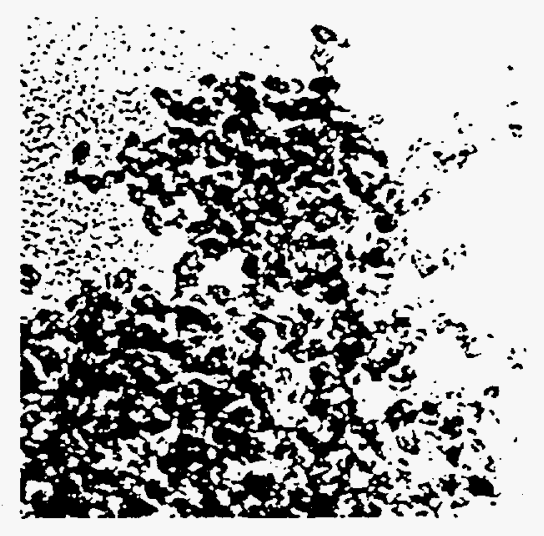

$500 \AA$

Figure 3 


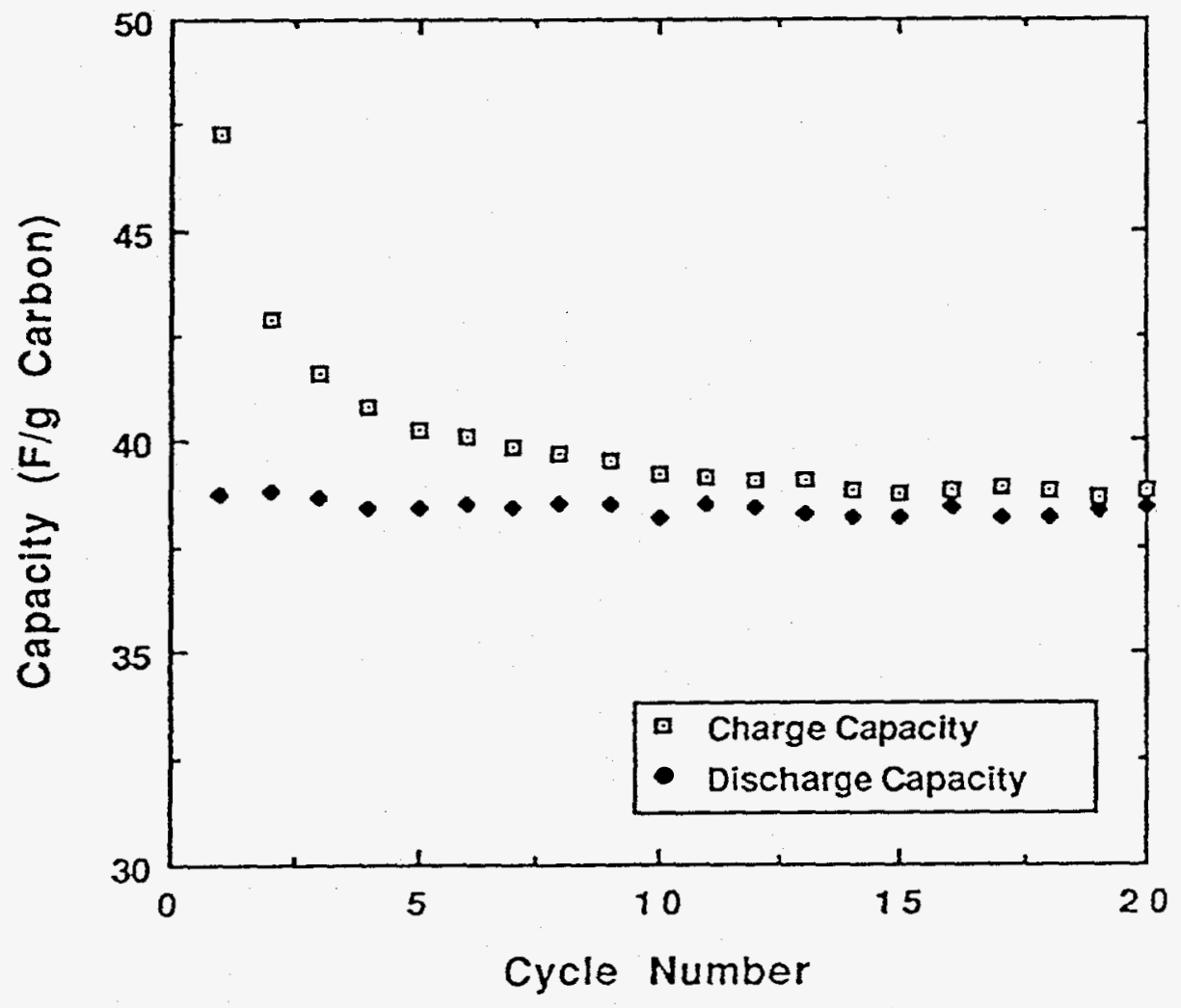

Figure 4 


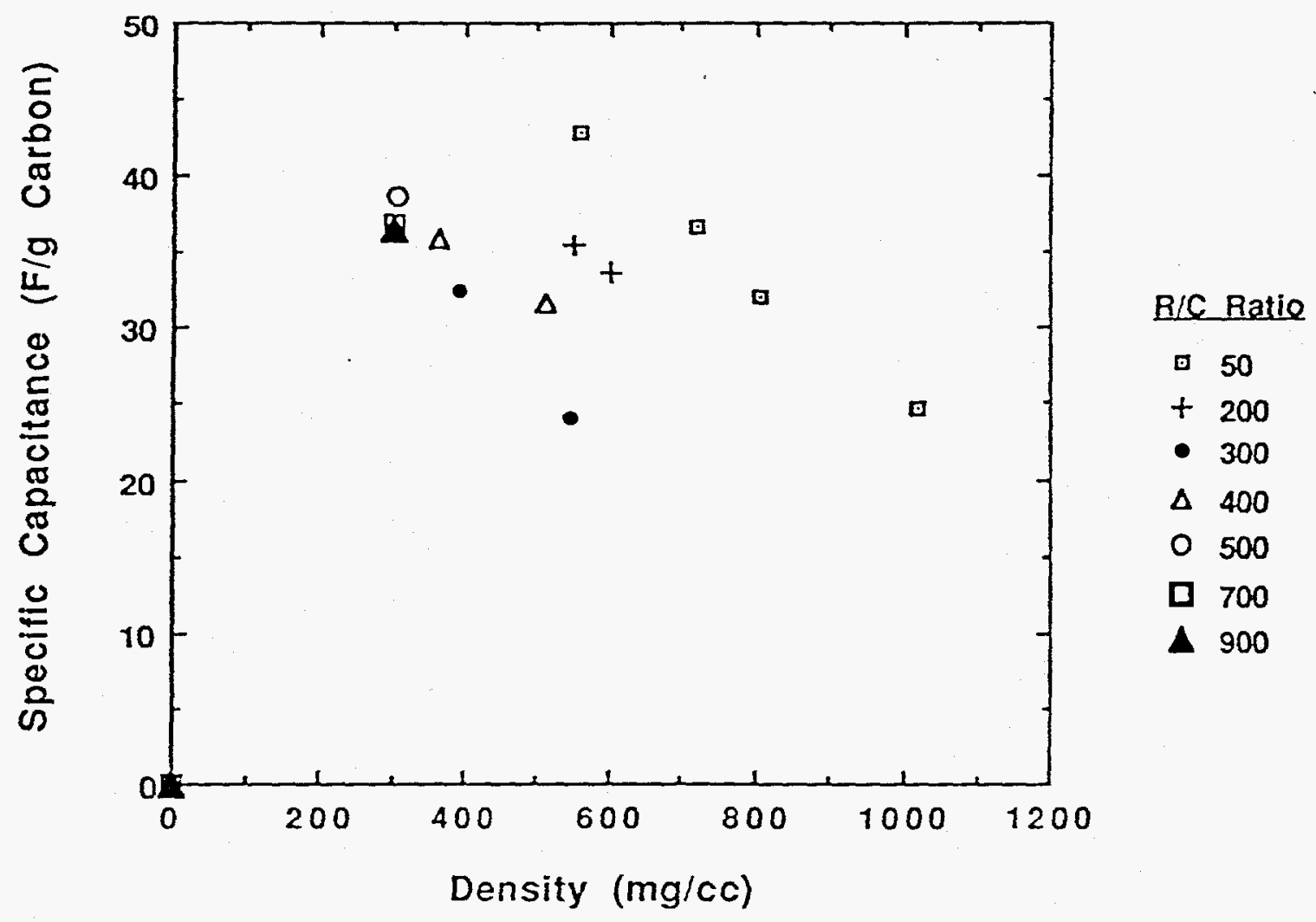

Figure 5 


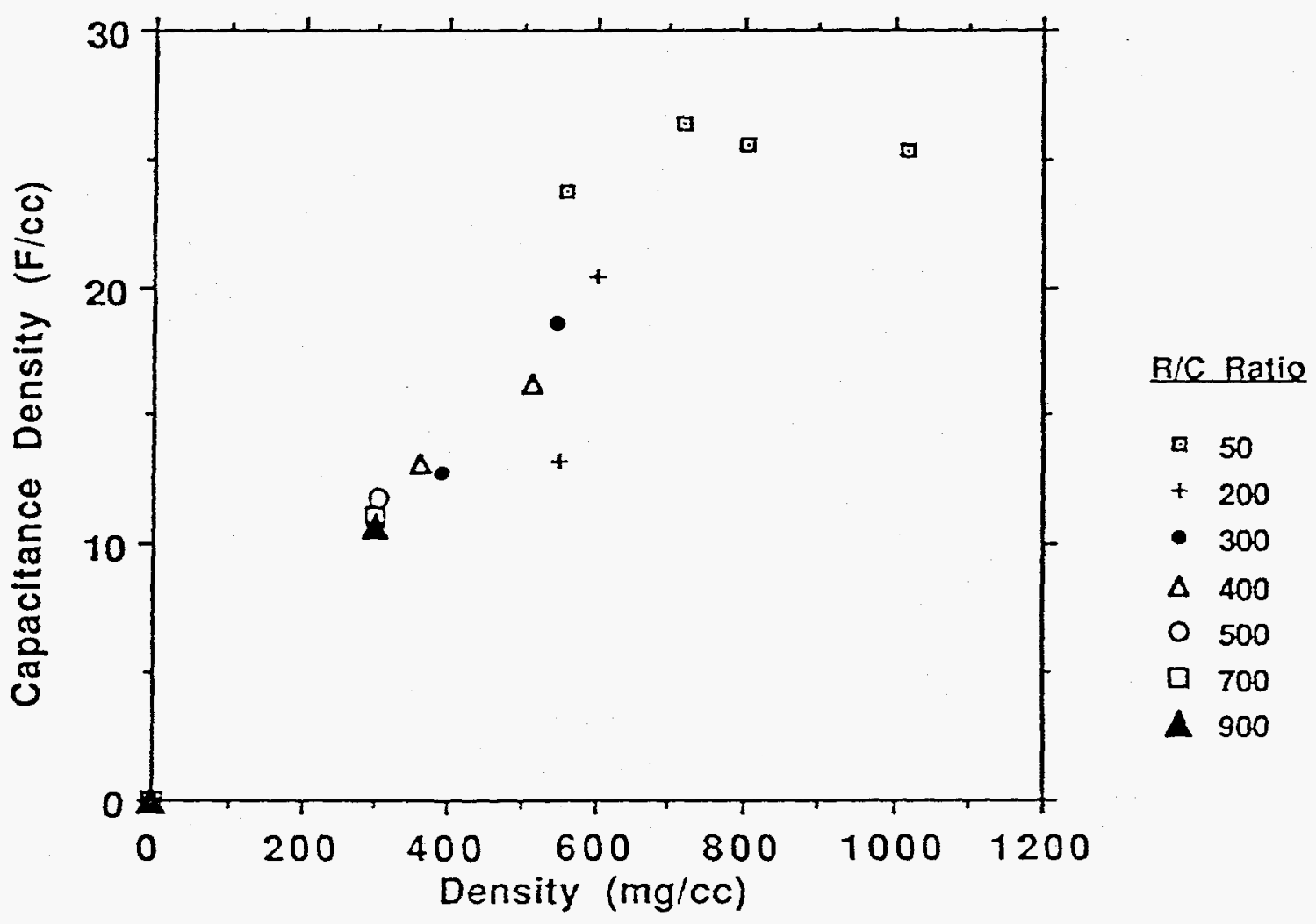

Figure 6 


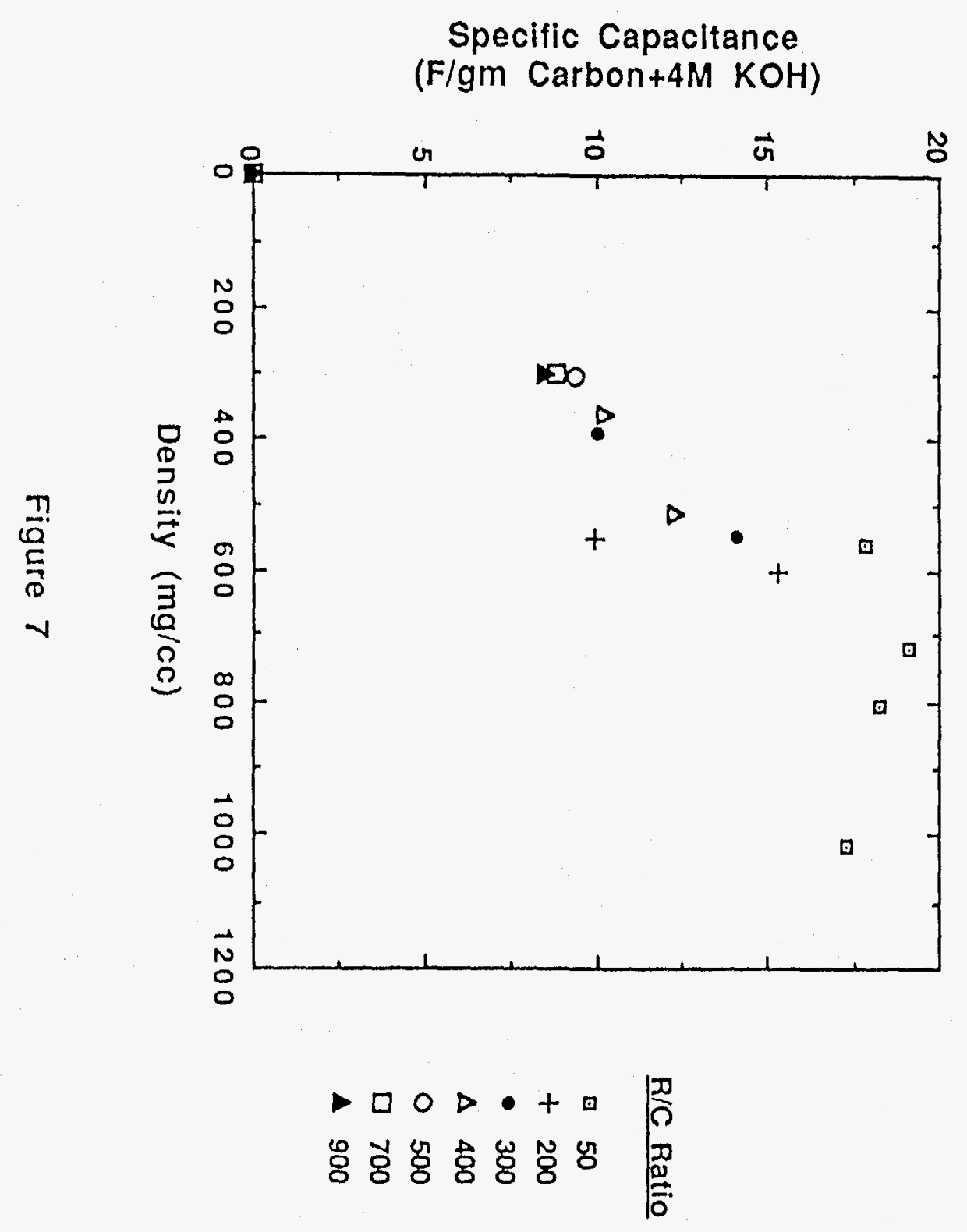




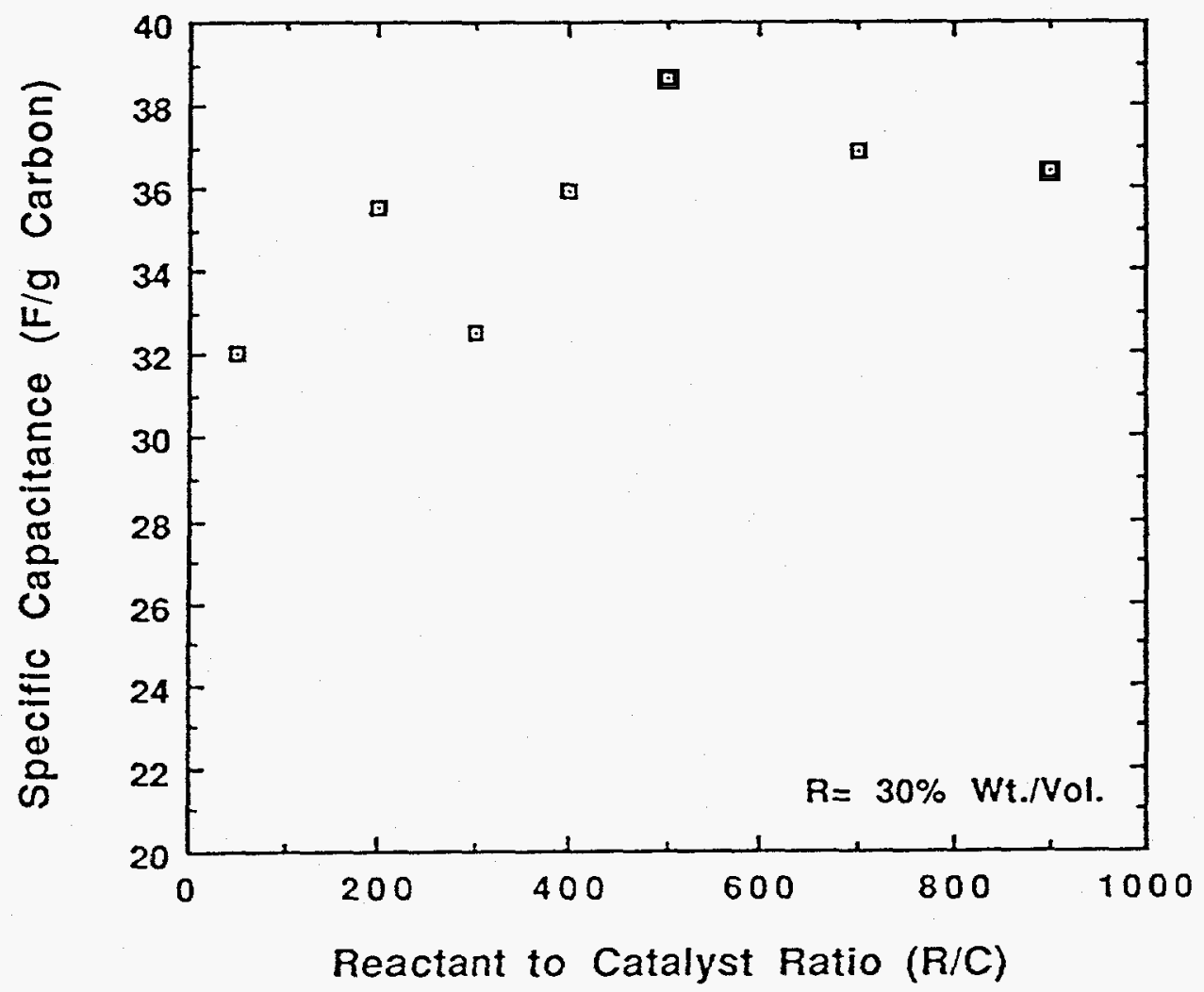

Figure 8 


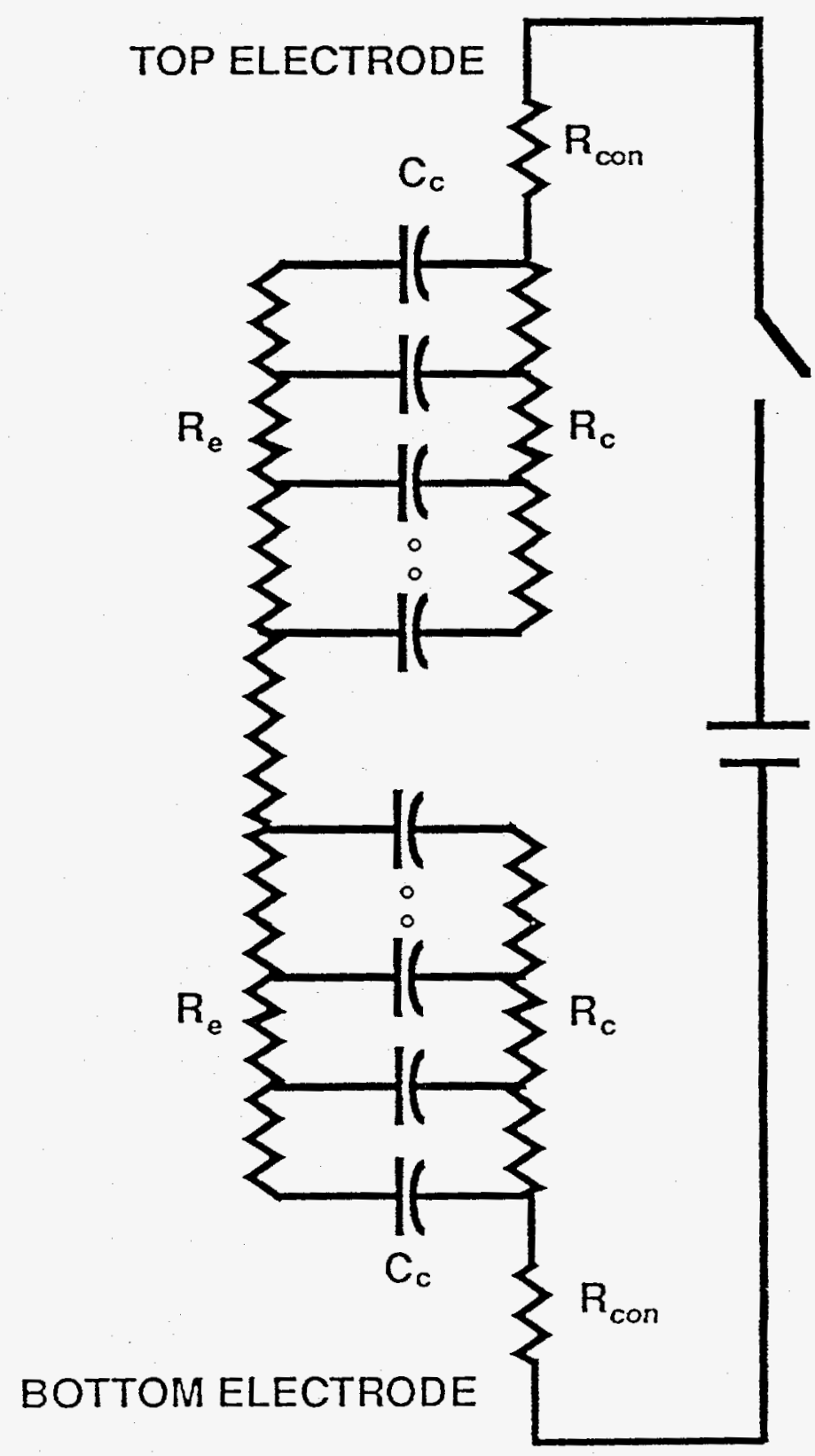

Aerocapacitor Equivalent Circuit

Figure 9 


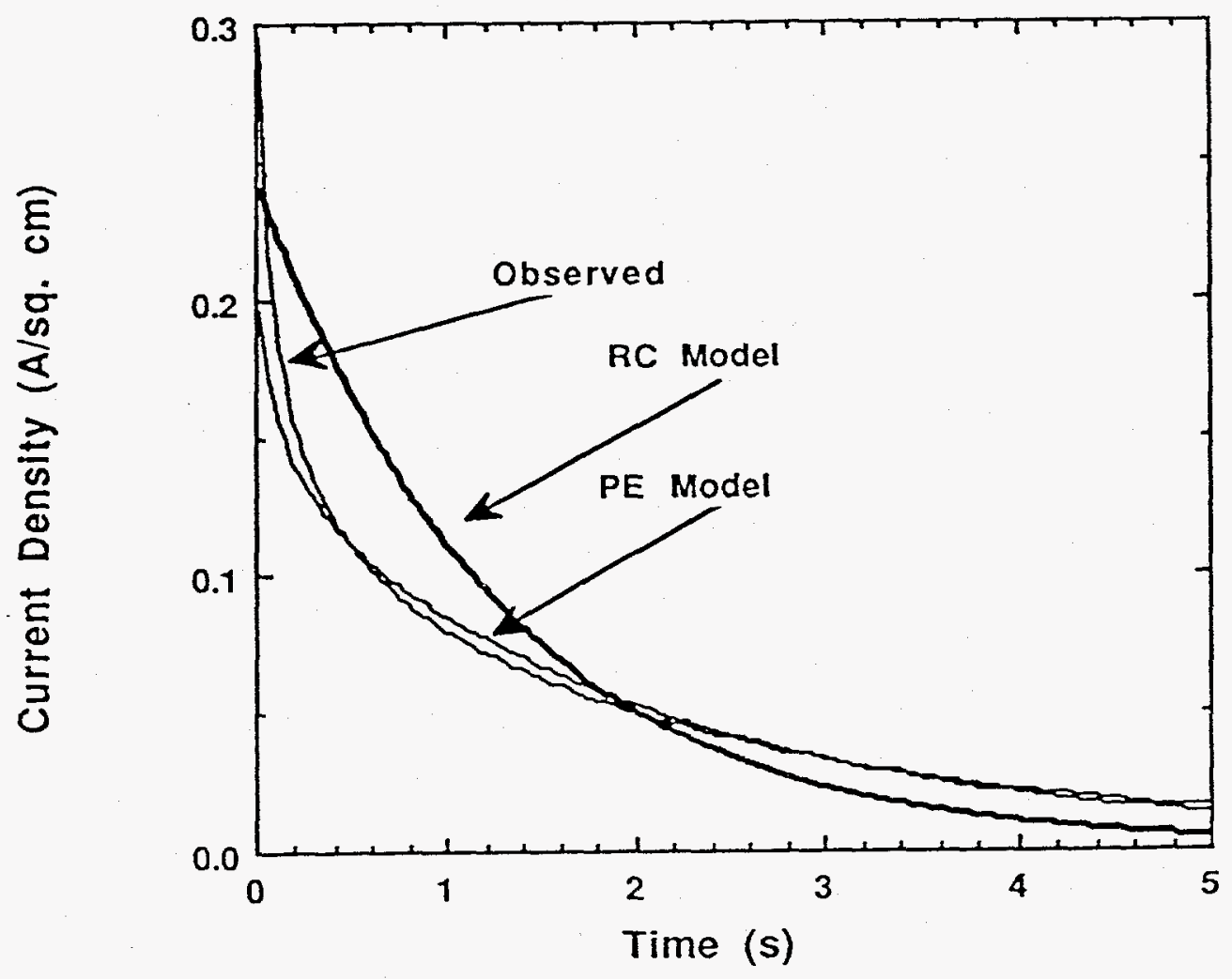

Fiaure 10 